\title{
GMR
}

\section{Tetrandrine induces microRNA differential expression in human hypertrophic scar fibroblasts in vitro}

\author{
P. Ning ${ }^{1,2 *}$, Y. Peng ${ }^{1 *}$, D.W. Liu ${ }^{1}$, Y.H. Hu ${ }^{1,3}$, Y. Liu ${ }^{1}$ and D.M. Liu ${ }^{4}$ \\ ${ }^{1}$ Burns Institute, The First Affiliated Hospital of Nanchang University, \\ Nanchang, Jiangxi, China \\ 2Department of ICU, Qingyuan People's Hospital, Qingyuan, Guangdong, China \\ ${ }^{3}$ Jiangxi University of Traditional Chinese Medicine, Nanchang, Jiangxi, China \\ ${ }^{4}$ Medical College of Nanchang University, Nanchang, Jiangxi, China \\ ${ }^{*}$ These authors contributed equally to this study. \\ Corresponding author: D.W. Liu \\ E-mail: dewuliu@126.com \\ Genet. Mol. Res. 15 (1): gmr.15017288 \\ Received August 22, 2015 \\ Accepted October 15, 2015 \\ Published February 5, 2016 \\ DOI http://dx.doi.org/10.4238/gmr.15017288
}

ABSTRACT. MicroRNAs (miRNAs) have recently been shown to play a role in normal wound healing process. miRNAs may be linked to pathologic wound healing and closely related to the formation of hypertrophic scars. This study aimed to explore the effects of tetrandrine on the miRNA expression profile in human hypertrophic scar fibroblasts (HSFs) in vitro. HSFs were randomly divided into two groups: the tetrandrine treatment group and the control group. The experimental and control groups were collected and analyzed by miRNA array after a 48-h culture. Real-time reverse transcriptase-polymerase chain reaction (RT-PCR) was performed to confirm the array results. The targets of differentially expressed miRNA were functionally annotated using bioinformatic approaches. miRNA microarray analysis identified 193 differentially expressed miRNAs and the expression of 186 miRNAs in the experimental group decreased while that of 7 miRNAs increased compared to the control group. The most significantly 
downregulated miRNA was hsa-miR-1246, and hsa-miR-27b had the highest expression level. Significant differentially expressed miRNAs were predicted to be related to several important signaling pathways related to scar wound healing. The differential miRNA expression identified in this study provides the experimental basis for further understanding the antifibrosis effect of tetrandrine.

Key words: Fibroblasts; Hypertrophic scars; MicroRNA; Expression profile; Tetrandrine

\section{INTRODUCTION}

Hypertrophic scars result from an abnormal fibrous wound healing process and represent a connective tissue response to trauma, inflammation, surgery, or burns. It is believed that proliferation of fibroblasts plays an important role in hypertrophic scar formation and is involved in reepithelialization, extracellular matrix (ECM) deposition, neovascularization, and ECM remodeling (van der Veer et al., 2009). Both experimental and clinical researchers have shown that tetrandrine, a bisbenzylisoquinoline alkaloid isolated from the root of Stephania tetrandra, exerted antiinflammatory properties, attenuated ECM deposition, and exhibited antifibrogenic activity against fibroblasts (Reist et al., 1993; Huang and Hong, 1998; Oh and Lee, 2003). Our previous studies have provided evidence that tetrandrine significantly inhibits proliferation of hypertrophic scar fibroblasts (HSFs) and decreases the expression of DNA (Liu et al., 2001). However, the underlying mechanism remains unclear.

MicroRNAs (miRNAs) are a new class of regulatory noncoding single-stranded RNAs (19-22 nucleotides), which can suppress the expression of protein-coding genes by targeting the 3'-untranslated region (UTR) of messenger RNAs (mRNAs) and play a key role in cellular growth and differentiation, as well as in disease development (Bartel, 2004; Kloosterman and Plasterk, 2006; Zhao and Srivastava, 2007). It is predicted that up to $30 \%$ of human genes are regulated by miRNAs. In addition, each miRNA can target several hundred mRNA 3'-UTRs, making miRNAs a large family of 'regulatory' molecules (Aberdam et al., 2008). However, the anti-fibrosis metabolism mechanism of tetrandrine and whether it is related to miRNAs remains unclear. In this study, we tested the effects of tetrandrine on mRNA expression in HSFs and analyzed putative targets of differentially expressed miRNAs using bioinformatic approaches.

\section{MATERIAL AND METHODS}

\section{Fibroblast isolation and cell culture}

HSFs were established as a primary cell line from hypertrophic scar tissue obtained from severe burn patients who underwent orthopedic surgery at the Department of Plastic and Reconstructive Surgery of the First Affiliated Hospital of Nanchang University, China. Written informed consent was obtained according to the rules and regulations set by the Ethics Committee of the First Affiliated Hospital of Nanchang University.

Hypertrophic scar tissue was cut into 0.5 - to $1-\mathrm{mm}^{3}$ pieces using a pair of scissors, and the epidermis and dermis were isolated by digestion with $0.25 \%$ Trypsin + EDTA (Gibco, USA) at $4^{\circ} \mathrm{C}$ 
for $10-12 \mathrm{~h}$. The pieces were then placed in $25-\mathrm{cm}^{2}$ cell culture flasks (Corning, USA), and $5 \mathrm{~mL}$ culture medium containing Dulbecco's modified Eagle's medium (DMEM) with $100 \mathrm{U} / \mathrm{mL}$ penicillin and $100 \mathrm{U} / \mathrm{mL}$ streptomycin (Solarbio) and 10\% fetal bovine serum (HyClone, USA) was added. The flasks were maintained at $37^{\circ} \mathrm{C}$ in air containing $5 \% \mathrm{CO}_{2}$. The culture medium was changed (5 $\mathrm{mL}$ ) every 5 days. HSFs grew to fusion for 14 days and were then subcultured into $25-\mathrm{mm}^{2}$ culture flasks. Experiments were performed with early passage cells (4-6) (Russell and Witt, 1976).

\section{Drug treatment and morphological observation of cultured fibroblasts}

HSFs $\left(1 \times 10^{5}\right)$ seeded on 6 -well plates were subjected to different treatments: a control group consisting of fibroblasts cultured with DMEM only and a test group where $5 \mathrm{mg} / \mathrm{mL}$ tetrandrine (molecular formula $\mathrm{C}_{38} \mathrm{H}_{42} \mathrm{~N}_{2} \mathrm{O}_{6}$, Yingtao, China) was added to the culture medium based on our previous results indicating that the inhibition ratio of $\mathrm{HSFs}$ was $50.72 \%$ at $5 \mathrm{mg} / \mathrm{mL}$ tetrandrine (Zunwen et al., 2012). After adding the tetrandrine, morphological changes in the HSFs were observed with an inverted microscope, and photos were taken every $24 \mathrm{~h}$.

\section{Sample harvest}

After $72 \mathrm{~h}$, the test and control group cells were digested and made into single-cell suspensions. Then, the cells were centrifuged at $1000 \mathrm{rpm}$ for $5 \mathrm{~min}$ and the supernatant removed.

\section{Total RNA extraction and purification}

RNA was isolated using TRIZOL and then quantitated using a spectrophotometer. The total RNA quality was examined using formaldehyde denaturing gel. Total RNA from the cells was isolated using the mirVana ${ }^{\mathrm{TM}}$ miRNA Isolation Kit (Applied Biosystems) following the manufacturer protocol.

\section{miRNA microarray analysis}

We used $100 \mathrm{ng}$ miRNA to perform the in situ oligonucleotide microarray. Fluorescent miRNA was labeled using the miRNA Complete Labeling and Hyb Kit (Agilent, USA) according to the manufacturer protocol. The hybridization was carried out for $20 \mathrm{~h}$ at $55^{\circ} \mathrm{C}$ in a rotating hybridization oven according to the instructions. After hybridization, slides were washed and then scanned by AgilentHD_miRNA. The Feature Extraction (v10.7) software was required for analysis of the images and extraction of scan data. Then, the GeneSpring software was used for data normalization, and the criterium using for differentially expressed miRNAs analysis was an absolute fold-change of at least more than 1-fold.

\section{RT-PCR for miRNA expression analysis}

To validate the miRNA microarray data, the significantly upregulated and downregulated miRNAs were selected and analyzed by RT-PCR assays, which were carried out using a $7900 \mathrm{HT}$ Fast RealTime PCR system (Applied Biosystems). The miRNA-specific primers for hsa-miR-125b, hsa-miR-27b, and internal control U6 were purchased from Invitrogen (USA). Expression levels of each mature miRNA were evaluated using the comparative threshold cycle (Ct) method and 
normalized to those of U6 small nuclear RNA for each condition (calculated using the comparative Ct method and analyzed by $2^{-\Delta \Delta C t}$; Schmittgen and Livak, 2008).

\section{Prediction of mRNA target}

Three commonly used databases including miR, (http://www.microrna.org/microrna/home. do), PicTar (http://www.pictar.org/), and TargetScan (http://www.targetscan.org/) were used to obtain predicted gene targets for significantly differentially expressed miRNAs. The genes identified using at least two of the methods were considered potential target genes regulated by a given miRNA. Predicted target genes in combination with miRNA and whole-genome microarray data were used to visualize possible biological miRNA/mRNA processes correlating to HSF growth and/or differentiation. Then, the predicted target genes underwent enrichment analysis of cell signaling pathways using the Kyoto Encyclopedia of Genes and Genomes (KEGG) pathway database (Hua et al., 2009).

\section{RESULTS}

\section{Morphological changes in HSFs}

HSFs cultured for $48 \mathrm{~h}$ exhibited a long spindle-shaped structure with larger cell bodies. The cytoplasms of the fibroblasts were rich and showed multiple-angle shapes, which grew two or three different synaptic lengths (Figure 1A). Compared to the control cells, the number of HSFs treated with tetrandrine decreased, the shape of cells became smaller and round, and spindles became shorter or disappeared (Figure 1B).

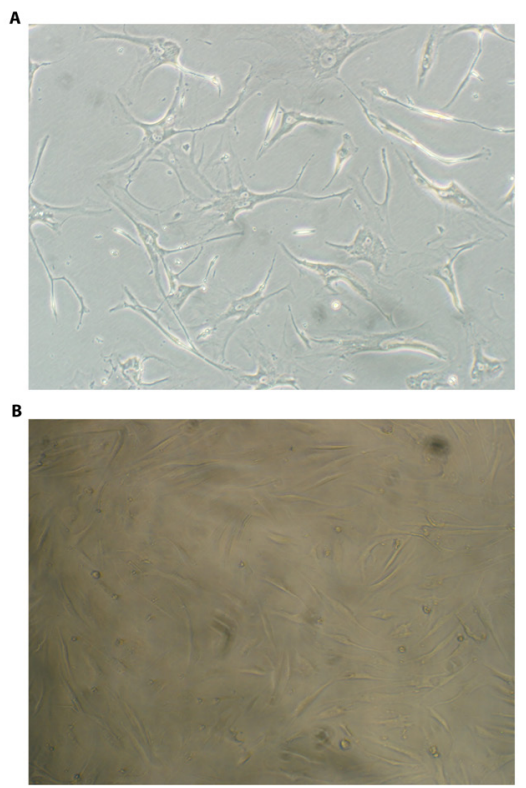

Figure 1. Morphological changes of hypertrophic scar fibroblasts (HSFs) observed under inverted microscope (magnification 200T). HSFs were subjected to different treatment: control group (A), tetrandrine group (B). It represents the morphological changes of HSFs for $48 \mathrm{~h}$. 
Table 1. Downregulated miRNAs in the test group relative to the control group.

\begin{tabular}{|c|c|c|c|}
\hline miRNA-ID & Raw experimental signal values (test group) & Raw experimental signal values (control group) & Absolute fold-change (test vs control) \\
\hline hsa-miR-1246 & 14.8059 & 295.8396 & 19.282063 \\
\hline hsa-miR-10b & 7.13783 & 71.5005 & 9.666621 \\
\hline hsa-miR-760 & 2.24873 & 22.43954 & 9.629608 \\
\hline hsa-miR-150* & 12.08515 & 117.3476 & 9.370315 \\
\hline hsa-miR-1268 & 15.42086 & 128.8487 & 8.063123 \\
\hline hsa-miR-939 & 22.99794 & 163.953 & 6.8795867 \\
\hline hsa-miR-378 & 7.06811 & 45.4653 & 6.2073846 \\
\hline hsa-miR-483-5p & 11.66605 & 72.784 & 6.020657 \\
\hline hsa-miR-1290 & 13.611179 & 83.731895 & 5.9364524 \\
\hline hsa-miR-1275 & 41.9974 & 240.9115 & 5.53563 \\
\hline hsa-miR-503 & 4.55466 & 26.109589 & 5.5319195 \\
\hline hsa-miR-30d & 4.70458 & 24.4761 & 5.020572 \\
\hline hsa-miR-1202 & 175.239 & 901.888 & 4.96654 \\
\hline hsa-miR-181b & 4.28493 & 20.67487 & 4.656192 \\
\hline hsa-miR-224 & 8.87527 & 41.6338 & 4.526854 \\
\hline hsa-miR-542-5p & 7.32674 & 34.3547 & 4.5248823 \\
\hline hsa-miR-1225-5p & 99.1514 & 446.079 & 4.341553 \\
\hline hsa-miR-542-3p & 4.43398 & 19.74572 & 4.297453 \\
\hline hsa-miR-630 & 37.1656 & 164.6234 & 4.27447 \\
\hline hsa-miR-188-5p & 24.547901 & 98.9035 & 3.8880258 \\
\hline hsa-miR-99a & 95.2809 & 374.3466 & 3.7914007 \\
\hline hsa-miR-1207-5p & 249.101 & 921.96497 & 3.5716655 \\
\hline hsa-miR-1226* & 7.88485 & 29.01783 & 3.5514302 \\
\hline hsa-miR-125a-3p & 23.97645 & 86.0822 & 3.4646585 \\
\hline hsa-miR-299-3p & 4.8526 & 17.40824 & 3.4618816 \\
\hline hsa-miR-1305 & 235.558 & 821.61597 & 3.3659143 \\
\hline hsa-miR-500a & 27.36765 & 93.7181 & 3.3045917 \\
\hline hsa-miR-1977 v14.0 & 7.07214 & 23.9922 & 3.2737923 \\
\hline hsa-miR-1914 ${ }^{*}$ & 150.7833 & 511.42902 & 3.2731354 \\
\hline $\begin{array}{l}\text { nsa-mik-1914 } \\
\text { hsa-miR-362-5p }\end{array}$ & $\begin{array}{l}950.1833 \\
.51801\end{array}$ & $\frac{511.42402}{30.55838}$ & $\begin{array}{l}3.2731534 \\
3.0982468\end{array}$ \\
\hline hsa-miR-1295 & 12.04883 & 38.6351 & 3.0943468 \\
\hline hsa-miR-134 & 39.161 & 123.9933 & 3.055458 \\
\hline hsa-miR-532-5p & 12.5388 & 39.5899 & 3.0469153 \\
\hline hsa-miR-30c & 5.37916 & 16.6203 & 2.981648 \\
\hline hsa-miR-424 & 135.9667 & 419.182 & 2.9751027 \\
\hline hsa-miR-101 & 11.2223 & 33.744667 & 2.9017177 \\
\hline hsa-miR-1308_v15.0 & 434.11072 & 1303.179 & 2.896913 \\
\hline hsa-miR-30e & 13.2306 & 38.25769 & 2.7904298 \\
\hline hsa-miR-575 & 87.0917 & 250.1585 & 2.7718544 \\
\hline hsa-miR-494 & 77.8722 & 223.0759 & 2.7644079 \\
\hline hsa-miR-886-3p_v15.0 & 199.30449 & 568.25476 & 2.7514274 \\
\hline hsa-miR-892b & 57.324 & 163.1691 & 2.7468398 \\
\hline hsa-miR-218 & 40.8108 & 114.9884 & 2.719009 \\
\hline hsa-miR-762 & 273.9874 & 768.546 & 2.706893 \\
\hline hsa-miR-26a & 112.953896 & 312.659 & 2.6711693 \\
\hline hsa-miR-23a* & 16.78239 & 45.90035 & 2.6393325 \\
\hline hsa-miR-31 & 72.4642 & 196.56601 & 2.6176813 \\
\hline hsa-miR-320c & 101.8523 & 275.8135 & 2.6132224 \\
\hline hsa-miR-638 & 218.59781 & 590.577 & 2.607129 \\
\hline hsa-miR-1288 & 109.0787 & 292.881 & 2.591094 \\
\hline hsa-miR-662 & 5.20603 & 13.94821 & 2.585495 \\
\hline hsa-miR-155 & 55.2021 & 147.10541 & 2.5716083 \\
\hline hsa-miR-152 & $\begin{array}{l}0.20<1 \\
19.8854\end{array}$ & 52.8124 & 2.5629108 \\
\hline hsa-miR-92a & $\begin{array}{l}1.0054 \\
126899\end{array}$ & 33.34922 & 25360584 \\
\hline hsa-miR-373* & 4.28093 & 11.2446 & 2.5347652 \\
\hline hsa-miR-195 & 34.71508 & 90.1275 & 2.505365 \\
\hline hsa-miR-202 & 96.22861 & 246.725 & 2.474235 \\
\hline hsa-miR-342-3p & 10.5277 & 26.3865 & 2.4186897 \\
\hline hsa-miR-497-op & $\frac{1.5211}{7.44844}$ & $\begin{array}{l}20.3000 \\
18.4124 \\
\end{array}$ & $\begin{array}{l}2.41000911 \\
2.3854864\end{array}$ \\
\hline hsa-miR-151-3p & 13.4891 & 32.79506 & 2.3461585 \\
\hline hsa-miR-99b & 22.57304 & 54.7146 & 2.3390799 \\
\hline hsa-let-7i & 832.487 & 2007.053 & 2.3265529 \\
\hline hsa-miR-423-5p & 5.87581 & 14.131 & 2.3207967 \\
\hline hsa-miR-1915 & 144.2714 & 345.15 & 2.308656 \\
\hline hsa-miR-320a & 69.0542 & 163.539 & 2.2854054 \\
\hline hsa-miR-1260 & 77.47149 & 183.04642 & 2.2800863 \\
\hline hsa-miR-381 & 13.2529 & 31.1877 & 2.2709332 \\
\hline hsa-miR-128 & 4.76358 & 11.1013 & 2.2489104 \\
\hline hsa-miR-501-5p & 27.15319 & 63.034397 & 2.240209 \\
\hline hsa-miR-137 & 52.1592 & 119.809494 & 2.2166247 \\
\hline hsa-miR-374b & 12.55825 & 28.3029 & 2.1748722 \\
\hline hsa-miR-199b-5p & 351.8671 & 789.69196 & 2.1657622 \\
\hline hsa-miR-125b & 2194.671 & 4902.39 & 2.1556098 \\
\hline hsa-miR-16 & 599.572 & $\begin{array}{l}490.05 \\
1313.446\end{array}$ & 2.1139898 \\
\hline hsa-miR-26b & 86.1997 & 188.4135 & 2.109299 \\
\hline hsa-miR-1224-5p & 35.1823 & $\begin{array}{l}700.4103 \\
76.369 \\
\end{array}$ & 2.0947142 \\
\hline hsa-miR-98 & 28.9707 & 62.66643 & 2.087411 \\
\hline hsa-miR-660 & 9.15352 & 19.6795 & 2.0747123 \\
\hline hsa-miR-654-3p & 16.0017 & 34.3716 & 2.072839 \\
\hline hsa-miR-196a & 276.8318 & 594.26404 & 2.0715487 \\
\hline hsa-miR-572 & 9.68648 & 20.7287 & 2.0650852 \\
\hline hsa-miR-31 ${ }^{*}$ & 56.4231 & 119.8061 & 2.049055 \\
\hline hsa-miR-222 & 36.456 & 76.92737 & 2.0363092 \\
\hline hsa-let-7e & 375.427 & 789.65796 & 2.0297637 \\
\hline hsa-miR-125a-5p & $\frac{310.427}{75.8074}$ & 158.9961 & 2.0239823 \\
\hline $\begin{array}{l}\text { nsa-mil-125a-5p } \\
\text { hsa-miR-324-3p }\end{array}$ & $\frac{15.8044}{29.401241}$ & 61.6354 & $\frac{2.0209020}{2.0230024}$ \\
\hline hsa-miR-625 & 5.16288 & 10.8205 & $\begin{array}{l}2.02000<4 \\
2.0224943\end{array}$ \\
\hline hsa-miR-151-5p & $\begin{array}{c}.10200 \\
99.916306\end{array}$ & 209.0674 & 2.0192115 \\
\hline hsa-miR-214 & 69.86972 & 145.8224 & 2.0140345 \\
\hline hsa-miR-199a-3p & 2086.856 & 4347.41 & 2.0103414 \\
\hline
\end{tabular}


Table 2. Upregulated miRNAs in the test group relative to the control group.

\begin{tabular}{l|c|c|c}
\hline miRNA-ID & Raw experimental signal values (test group) & Raw experimental signal values (control group) & Absolute fold-change (test vs control) \\
\hline hsa-miR-27b & 246.7309 & 171.95459 & 1.4868867 \\
\hline hsa-miR-29b-1* & 45.064598 & 32.8065 & 1.4234551 \\
\hline hsa-miR-193a-3p & 35.012 & 28.9008 & 1.2553804 \\
\hline hsa-miR-493* & 18.6228 & 16.9013 & 1.1410079 \\
\hline hsa-miR-100 & 1330.14 & 1253.593 & 1.0995347 \\
\hline hsa-miR-27a & 1042.83 & 1010.114 & 1.0698209 \\
\hline hsa-miR-29b & 1373.474 & 1334.3251 & 1.0666622
\end{tabular}

\section{Differential miRNA expression between the test group and the control group}

To distinguish the differentially expressed miRNAs, we examined the expression of miRNAs in the test and control groups using an miRNA microarray. Only miRNAs with changes of at least 1-fold were included. By this criterion, 193 miRNAs were identified, among which 186 were downregulated (Table 1 shows miRNAs whose expression exceeded 2-fold) and 7 were upregulated (Table 2) in the test group compared to that in the control group.

\section{Validation of the microarray data by RT-PCR}

To validate the results from the miRNA microarray, we further employed RT-PCR to measure the abundance of the miRNA, including downregulated hsa-miRNA-125b and upregulated hsa-miRNA-27b. The $2^{-\Delta \Lambda C t}$ values showed that hsa-miR-27b (1.92>1.0) was upregulated, while hsa-miR-125b $(0.74<1.0)$ was downregulated. The RT-PCR data indicated that the transcriptional level of hsa-miRNA-125b and hsa-miRNA-27b coincided perfectly with the microarray results.

\section{Putative targets of miRNAs and functional analysis by bioinformatics}

All differentially expressed miRNAs were subjected to target gene prediction. Each miRNA potentially regulates many targets. To decrease the total number of false-positive targets, targets predicted by both methods were considered putative candidates. After carefully analyzing the putative targets, we identified targets for each miRNA. To elucidate the target pathways of miRNAs, KEGG pathway analysis was employed to clarify the biological significance of these potential target pathways, helping us to further understand the biological processes and corresponding metabolic networks regulated by potential miRNAs. We found that many targets played significant roles in several signaling pathways that play important roles in wound repair including vascular endothelial growth factor (VEGF), apoptosis, and the cell cycle. Table 3 shows part of the putative targets of hsa-miR-125b and hsa-miR-27b.

Table 3. Putative targets of hsa-miR-125b and hsa-miR-27b.

\begin{tabular}{l|l|l}
\hline miRNA-ID & Targets & Gene name \\
\hline hsa-miR-125b & STARD13 & Star-related lipid transfer (START) domain containing 13 \\
\hline & COL4A3 & Collagen, type IV, alpha 3 \\
\hline & FGFR2 & Fibroblast growth factor receptor 2 \\
\hline & BCL2L12 & BCL2-like 12 \\
\hline & TNFSF4 & Tumor necrosis factor (ligand) superfamily, member 4 \\
\hline & ATP10D & Atpase, Class V, type 10D \\
\hline & VEGFC & Vascular endothelial growth factor C \\
\hline & APAF1 & Apoptotic protease activating factor \\
\hline & COL19A1 & Collagen, type XIX, alpha 1 \\
\hline & GDF8 & Growth differentiation factor 8 \\
\hline & EGFR & Epidermal growth factor receptor
\end{tabular}




\section{DISCUSSION}

Hypertrophic scar formation occurs when the equilibrium between positive and negative cytokines stimulated by inflammation and the synthesis and metabolism of ECM is broken (van der Veer et al., 2009). The abnormal biological behavior of fibroblasts plays a critical role in the scar formation process. Tetrandrine is a bisbenzylisoquinoline alkaloid derived from S. tetrandra. Previous pharmacological and clinical studies have shown that tetrandrine possesses antiinflammatory, anti-proliferative, immunosuppressive, and antitumor activities (Dong et al., 1997; Lai et al., 1998; Xie et al., 2002; Yoo et al., 2002; Lee et al., 2002; Kuo and Lin, 2003; Wang et al., 2004). In recent years, it was discovered that tetrandrine can inhibit proliferation of human Tenon's capsule fibroblasts and differentiation of osteoclasts (Takahashi et al., 2012; Li et al., 2012). In our previous studies, we showed that tetrandrine inhibited proliferation of HSFs and synthesis of collagen and DNA (Liu et al., 2001). However, it is still unclear how tetrandrine inhibits HSFs. MicroRNAs are known to play critical roles in development, cell proliferation, and other fundamental cellular processes (Bartel, 2004; Zhao and Srivastava, 2007). Our previous studies have confirmed distinct differences in miRNA expression between human hyperplastic scar tissue and normal skin, which may be closely correlated to the formation, development, and evolution of hyperplastic scarring (Ning et al., 2012). Furthermore, Wilmink et al. (2010) have shown that dermal fibroblasts differentially express 123 miRNAs when exposed to hyperthermia using an miRNA microarray. In this study, we identified 193 potential miRNAs that were differentially expressed between the tetrandrine test group and the control group with 186 miRNAs downregulated and 7 upregulated.

Some miRNAs identified in this study have been shown to play important roles in some cellular mechanisms. Gutierrez et al. (2011) demonstrated that thyrotroph embryonic factor is downregulated by miR-125b through activation of p53 and this novel regulation pathway helps determine the actin distribution and the shape of fibroblasts. Moreover hsa-miR-125b was observed to regulate cell proliferation and differentiation in both breast cancer and ovarian cancer cell lines and plays an important role in osteoblastic differentiation (lorio et al., 2005; Mizuno et al., 2008; Guan et al., 2011). Hsa-miR-125a-3p and hsa-miR-125a-5p were found to affect the migration and invasion of lung cancer cells, while hsa-miR-99a was found to affect the differentiation of keratinocytes (Jiang et al., 2010; Lerman et al., 2011). Recent evidence has shown that hsa-miR-155 may promote cell proliferation by regulating its target genes and can regulate the expression of the angiotensin II type 1 receptor in primary human lung fibroblasts (Kong et al., 2010; Martin et al., 2013). While upregulated in the test group, hsa-miR-29b has been found to inhibit the expression of collagen 1 protein in skin fibroblasts by the way of classic mRNA transcriptional regulation in vitro (Wang et al., 2011). The results of the study by Crist et al. (2009) showed that overexpression of an miR-27b transgene in Pax3-positive cells in the embryo leads to downregulation of Pax3, resulting in interference with progenitor cell migration and in premature differentiation. Furthermore, miR$27 \mathrm{~b}$ inhibitors were transfected into cultures of adult muscle satellite cells that normally express miR-27b at the onset of differentiation, which resulted in continuing Pax3 expression leading to more proliferation and a delay in the onset of differentiation.

To obtain a better understanding of the functional significance of miRNA, it was important to identify and validate the miRNA targets. In this study, hundreds of target genes were predicted, including several key mediators of cellular signaling pathways and some ECM proteins. Among them, we analyzed the putative targets of hsa-miR-125b and hsa-miR-27b, which were validated by RT-PCR. According to the results, these targets were involved in several signaling pathways 
P. Ning et al.

such as VEGF, the cell cycle, and apoptosis. The BCL2 protein played a key role in apoptosis, cell migration, proliferation, and differentiation (Cory and Adams, 2002). COL4 was closely related with collagen formation, and fibroblast growth factor was important for fibroblast growth (van der Veer et al., 2009). VEGF, the target gene of hsa-miR-27b, was not only an important growth factor for promoting endothelial cell proliferation but also played an important role in protein synthesis and the formation of granulation tissue in the inflammatory and wound repair proliferative phases (Ferrara et al., 2003). Moreover, the target genes of hsa-miR-27b including COL19A1, GDF8, and EGFR were also related to collagen formation, cell differentiation, and epidermal growth. GDF8 has been proven to be a pro-fibrogenic factor that promotes fibroblast proliferation and ECM synthesis in tendons and ligaments (van der Veer et al., 2009; Fulzele et al., 2010). miRNAs might contribute to the anti-fibrosis properties of tetrandrine by regulating its targets and influencing multiple-signaling pathways.

As a traditional Chinese medicine, tetrandrine has been used for the treatment of arthritis, arrhythmia, hypertension, inflammation, and silicosis for years in the clinic and as a therapeutic (Fang and Fang, 1996; Pang and Hoult, 1997; Shen et al., 2001). However, tetrandrine has not been utilized as a clinical treatment for hypertrophic scarring because its mechanism is unknown. This study has identified the differentially expressed miRNAs in HSFs treated with tetrandrine through genomic profiling, and the putative targets of these altered miRNAs are most likely involved in multiple signaling pathways that have previously been shown to be implicated in cellular growth. Hence, certain miRNAs might contribute to the anti-fibrosis of tetrandrine in HSFs through the signaling pathways of these targets.

\section{ACKNOWLEDGMENTS}

Research supported by a grant from the National Natural Science Foundation of China (\#81060323).

\section{REFERENCES}

Aberdam D, Candi E, Knight RA and Melino G (2008). miRNAs, 'stemness' and skin. Trends Biochem. Sci. 33: 583-591. http:// dx.doi.org/10.1016/j.tibs.2008.09.002

Bartel DP (2004). MicroRNAs: genomics, biogenesis, mechanism,and function. Cell 116: 281-297. http://dx.doi.org/10.1016/ S0092-8674(04)00045-5

Cory S and Adams JM (2002). Bcl-2 family: regulators of cellular life- and-death switch. Nat. Rev. Cancer 2: 647-656. http:// dx.doi.org/10.1038/nrc883

Crist CG, Montarras B, Pallafacchina G, Rocancourt D, et al. (2009). Muscle stem cell behavior is modified by microRNA-27 regulation of Pax3 expression. Proc. Natl. Acad. Sci. U. S. A. 106: 13383-13387. http://dx.doi.org/10.1073/ pnas.0900210106

Dong Y, Yang MM and Kwan CY (1997). In vitro inhibition of proliferation of HL-60 cells by tetrandrine and coriolus versicolor peptide derived from Chinese medicinal herbs. Life Sci. 60: PL135-140. http://dx.doi.org/10.1016/S0024-3205(96)00695-9

Fang JH and Fang YH (1996). Tetrandrine: Pharmacology and clinical usefulness. Chin. Pharm. J. 31: 454-457.

Ferrara N, Gerber HP and LeCouter J (2003). The biology of VEGF and its receptors. Nat. Med. 9: 669-676. http://dx.doi. org/10.1038/nm0603-669

Fulzele S, Arounleut P, Cain M, Herberg S, et al. (2010). Role of myostatin (GDF-8) signaling in the human anterior cruciate ligament. J. Orthopaedic Res. 28: 1113-1118.

Guan Y, Yao H, Zheng Z, Qiu G, et al. (2011). MiR-125b targets BCL3 and suppresses ovarian cancer proliferation. Int. J. Cancer 128: 2274-2283. http://dx.doi.org/10.1002/ijc.25575

Gutierrez O, Berciano MT, Lafarga M and Fernandez-Luna JL (2011). A novel pathway of TEF regulation mediated by microRNA-125b contributes to the control of actin distribution and cell shape in fibroblasts. PLoS One 6: e17169. http:// dx.doi.org/10.1371/journal.pone.0017169 
Hua YJ, Tang ZY, Tu K, Zhu L, et al. (2009). Identification and target prediction of miRNAs specifically expressed in rat neural tissue. BMC Genomics 10: 214. http://dx.doi.org/10.1186/1471-2164-10-214

Huang YT and Hong CY (1998). Tetrandrine. Cardiovasc. Drug. Rev. 16: 1-15. http://dx.doi.org/10.1111/j.1527-3466.1998. tb00341.x

Iorio MV, Ferracin M, Liu CG, Veronese A, et al. (2005). MicroRNA gene expression deregulation in human breast cancer. Cancer Res. 65: 7065-7070. http://dx.doi.org/10.1158/0008-5472.CAN-05-1783

Jiang L, Huang Q, Zhang S, Zhang Q, et al. (2010). Has-125a-3p and hsa-miR-125a-5p are downregulated in non-small cell lung cancer and have inverse effects on invasion and migration of lung cancer cells. BMC Cancer 10: 318. http://dx.doi. org/10.1186/1471-2407-10-318

Kloosterman WP and Plasterk RH (2006). The diverse functions of microRNAs in animal development and disease. Dev. Cell 11: 441-450. http://dx.doi.org/10.1016/j.devcel.2006.09.009

Kong W, He LL, Coppola M, Guo J, et al. (2010). MicroRNA-155 regulates cell survival, growth, and chemosensitivity by targeting FOXO3a in breast cancer. J Biol Chem. 285: 17869-17879. http://dx.doi.org/10.1074/jbc.M110.101055

Kuo PL and Lin CC (2003). Tetrandrine-induced cell cycle arrest and apoptosis in Hep G2 cells. Life Sci. 73: 243-252. http:// dx.doi.org/10.1016/S0024-3205(03)00266-2

Lai YL, Chen YJ, Wu TY, Wang SY, et al. (1998). Induction of apoptosis in human leukemic U937 cells by tetrandrine. Anticancer Drugs 9: 77-81. http://dx.doi.org/10.1097/00001813-199801000-00009

Lee JH, Kang GH, Kim KC, Kim KM, et al. (2002). Tetrandrine-induced cell cycle arrest and apoptosis in A549 human lung carcinoma cells. Int. J. Oncol. 21: 1239-1244.

Lerman G, Avivi C, Mardoukh C, Barzilai A, et al. (2011). MiRNA expression in psoriatic skin: reciprocal regulation of hsa-miR99a and IGF-1R. PLoS One 6: e20916. http://dx.doi.org/10.1371/journal.pone.0020916

Li D, Sun M and Li QC (2012). Effect of tetrandrine eye drops on expression of apoptotic protein and transforming growth factor-b2 in human Tenon capsule fibroblast in vitro. Chin. J. Exp. Ophthalmol. 30: 218-222.

Liu DW, Li GH, Liu DM and Cao Y (2001). Effects of tetrandrine on the synthesis of collagen and scar-derived fibroblast DNA. Zhonghua Shao Shang Za Zhi 17: 222-224.

Martin MM, Lee EJ, Buckenberger JA, Schmittgen TD, et al. (2013). MicroRNA-155 regulates human angiotensin II type 1 receptor expression in fibroblasts. J. Biol. Chem. 288: 4226. http://dx.doi.org/10.1074/jbc.M601496200

Mizuno Y, Yagi K, Tokuzawa Y, Kanesaki-Yatsuka Y, et al. (2008). miR-125b inhibits osteoblastic differentiation by down-regulation of cell proliferation. Biochem. Biophys. Res. Commun. 368: 267-272. http://dx.doi.org/10.1016/j. bbrc.2008.01.073

Ning P, Liu DW, Mao YG, Peng Y, et al. (2012). Differential expression profile of microRNA between hyperplastic scar and normal skin. Zhonghua Yi Xue Za Zhi 92: 692-694.

Oh SH and Lee BH (2003). Induction of apoptosis in human hepatoblastoma cells by tetrandrine via caspase-dependent Bid cleavage and cytochrome crelease. Biochem. Pharmacol. 66: 725-731. http://dx.doi.org/10.1016/S0006-2952(03)00397-6

Pang L and Hoult JR (1997). Cytotoxicity to macrophages of tetrandrine, an antisilicosis alkaloid, accompanied by an overproduction of prostaglandins. Biochem. Pharmacol. 53: 773-782. http://dx.doi.org/10.1016/S0006-2952(96)00817-9

Reist RH, Dey RD, Durham JP, Rojanasakul Y, et al. (1993). Inhibition of proliferative activity of pulmonary fibroblasts by tetrandrine. Toxicol. Appl. Pharmacol. 122: 70-76. http://dx.doi.org/10.1006/taap.1993.1173

Russell JD and Witt WS (1976). Cell size and growth characteristics of cultured fibroblasts isolated from normal and keloid tissue. Plast. Reconstr. Surg. 57: 207-212. http://dx.doi.org/10.1097/00006534-197602000-00014

Schmittgen TD and Livak KJ (2008). Analyzing real-time PCR data by the comparative C(T) method. Nat. Protoc. 3: $1101-1108$. http://dx.doi.org/10.1038/nprot.2008.73

Shen YC, Chou CJ, Chiou WF and Chen CF (2001). Anti-inflammatory effects of the partially purified extract of radix Stephaniae tetrandrae: comparative studies of its active principles tetrandrine and fangchinoline on human polymorphonuclear leukocyte functions. Mol. Pharmacol. 60: 1083-1090.

Takahashi T, Tonami Y, Tachibana M, Nomura M, et al. (2012). Tetrandrine prevents bone loss in sciatic-neurectomized mice and inhibits receptor activator of nuclear factorkB ligand-induced osteoclast differentiation. Biol. Pharm. Bull. 35: 17651774. http://dx.doi.org/10.1248/bpb.b12-00445

Van der Veer WM, Bloemen MC, Ulrich MM, Molema G, et al. (2009). Potential cellular and molecular causes of hypertrophic scar formation. Burns 35: 15-29. http://dx.doi.org/10.1016/j.burns.2008.06.020

Wang G, Lemos JR and ladecola C (2004). Herbal alkaloid tetrandrine: from an ion channel blocker to inhibitor of tumor proliferation. Trends Pharmacol. Sci. 25: 120-123. http://dx.doi.org/10.1016/j.tips.2004.01.009

Wang YL, Wang ZL and Yang MF (2011). Inhibitory effects of microRNA-29b on collagen 1 in skin fibroblasts. Chin. J. Exp Surg. 28: 540-542.

Wilmink GJ, Roth CL, Ibey BL, Ketchum N, et al. (2010). Identification of microRNAs associated with hyperthermia-induced 
cellular stress response. Cell Stress Chaperones 15: 1027-1038. http://dx.doi.org/10.1007/s12192-010-0189-7

Xie QM, Tang HF, Chen JQ and Bian RL (2002). Pharmacological actions of tetrandrine in inflammatory pulmonary diseases. Acta Pharmacol. Sin. 23: 1107-1113.

Yoo SM, Oh SH, Lee SJ, Lee BW, et al. (2002). Inhibition of proliferation and induction of apoptosis by tetrandrine in HepG2 cells. J. Ethnopharmacol. 81: 225-229. http://dx.doi.org/10.1016/S0378-8741(02)00082-X

Zhao Y and Srivastava D (2007). A developmental view of micro-RNA function. Trends Biochem. Sci. 32: 189-197. http://dx.doi. org/10.1016/j.tibs.2007.02.006

Zunwen L, Shizhen Z, Dewu L, Yungui M, et al. (2012). Effect of tetrandrine on the TGF- $\beta$-induced smad signal transduction pathway in human hypertrophic scar fibroblasts in vitro. Burns 38: 404-413. http://dx.doi.org/10.1016/j.burns.2011.08.013 